\title{
Hydrodynamics-driven uncertainty study in simulating terrestrial carbon cycle with a coupled water-carbon cycle model
}

\section{Guodong Sun ( $\nabla$ sungd@mail.iap.ac.cn )}

Institute of Atmospheric Physics Chinese Academy of Sciences

Mu Mu

Fudan University

\section{Research Letter}

Keywords: net primary production, hydrological physical process, uncertainty, sensitivity of parameter combination

Posted Date: November 18th, 2020

DOI: https://doi.org/10.21203/rs.3.rs-108448/v1

License: (c) (i) This work is licensed under a Creative Commons Attribution 4.0 International License.

Read Full License 


\title{
Hydrodynamics-driven uncertainty study in simulating terrestrial carbon cycle with a coupled water-carbon cycle model
}

\author{
Guodong $\operatorname{Sun}^{1,3, *}$ and $\mathrm{Mu} \mathrm{Mu}{ }^{2}$ \\ ${ }^{1}$ State Key Laboratory of Numerical Modeling for Atmospheric Sciences and Geophysical Fluid Dynamics \\ (LASG), Institute of Atmospheric Physics, Chinese Academy of Sciences, Beijing 100029, China \\ ${ }^{2}$ Institute of Atmospheric Sciences, Fudan University, Shanghai 200433, China \\ ${ }^{3}$ University of Chinese Academy of Sciences, Beijing 100049 China
}

Corresponding author: Guodong Sun (sungd@mail.iap.ac.cn) 


\section{Abstract}

In this study, an uncertainty degree of net primary production (NPP) simulation or prediction is estimated due to uncertainty of hydrodynamic processes. The Lund-Potsdam-Jena Wetland Hydrology and Methane Dynamic Global Vegetation Model (LPJ-WHyMe DGVM), which could describe the interaction between terrestrial carbon cycle and hydrological cycle, is applied to evaluate the above issue. Four regions with different climate backgrounds in China are chosen to explore different behaviors about the influence of the simulated NPP to hydrological physical processes on. It is found that the error of NPP modeling is $198.5 \mathrm{~g} \mathrm{C} \mathrm{m}^{-2} \mathrm{yr}^{-1}(48.6 \%)$ in the arid and semiarid region of northern China due to the uncertainties in the hydrological processes, which is greater than those in other three regions. The errors of NPP modeling are $88.4 \mathrm{~g} \mathrm{C} \mathrm{m}^{-2} \mathrm{yr}^{-1}(19.1 \%)$ in northeastern China, $117.0 \mathrm{~g} \mathrm{C} \mathrm{m}^{-2}$ $\mathrm{yr}^{-1}(21.1 \%)$ in southern China, and $64.4 \mathrm{~g} \mathrm{C} \mathrm{m}^{-2} \mathrm{yr}^{-1}(13.2 \%)$ in the semi-humid region of northern China. Further numerical experiments reveal that the simulation ability of the NPP could be enhanced by reducing all hydrological parameter errors. Our results demonstrate the importance of hydrological processes to the simulation and prediction of the NPP.

Keywords: net primary production; hydrological physical process; uncertainty; sensitivity of parameter combination 


\section{Introduction}

Terrestrial carbon cycle acts as an important element to regulate atmospheric $\mathrm{CO}_{2}$ concentrations and climate changes in our Earth (Heimann Reichstein 2008; Gurney and Eckels 2011; Anav et al., 2013; Luo et al., 2015). Among the factors affecting the change of terrestrial carbon cycle, the hydrological cycle plays an important role (Yu et al., 2008; Vicente-Serrano et al., 2013; Bao et al., 2018). Both the carbon flux and the carbon stock in the terrestrial carbon cycle are affected by the hydrological cycle, such as precipitation, soil moisture, and evapotranspiration. Therefore, it is necessary to investigate the response of the terrestrial carbon cycle to the hydrological cycle.

Thus far, many efforts have been devoted to probe the feedback of water-related physical processes on the terrestrial carbon cycling with observational campaigns and models simulations (Baker et al., 2008; Scott-Denton et al., 2013). For example, Schwalm et al. (2011) used eddy covariance data, and found that there was no consistent trend in global scale in net ecosystem productivity (NEP), gross primary productivity (GPP), and ecosystem respiration (Ra) resulting from hydrological change. However, there were positive or negative trends in the three parts of terrestrial carbon cycling due to hydrological change in different continental scales. Process-based terrestrial ecosystem models are also vital tools to understand the terrestrial carbon cycle and its response to hydrological changes. Unreal represent about the response of the terrestrial carbon cycling to water may be a main reason to not in agreement with observations. Sakaguchi et al. (2011) stated that the simulation errors of the GPP stem from the new photosynthesis and soil hydrology with the 
Community Land Model (CLM). And the results implied the importance of owning realistic water cycles (Huang et al., 2016). With considering the soil freeze-thaw processes and the availability of liquid soil water, the simulated vegetation carbon density using the Lund-Potsdam-Jena (LPJ) model was comparable to field measurements in Siberia (Beer et al., 2007). Although there are workers to stress the important of hydrological cycle, the uncertainties still exist for simulation and prediction of the terrestrial carbon cycle. Huang et al. (2016) checked the response with CMIP5 models, and found that oversensitivity of CMIP5 models to drought for the GPP compared to the observation. In different wet and dry extremes, the variations of the GPP ranged from -5.30 to $-30.28 \mathrm{GtC}$, and $3.64 \mathrm{GtC}$ to $14.90 \mathrm{GtC}$, which are different from the magnitude of field observations employing more than 20 CMIP5 models. McGuire et al. (2016) stated that the simulated soil carbon and vegetation carbon were from 306 to $2268 \mathrm{Pg} \mathrm{C}$, and 17 to $192 \mathrm{Pg} \mathrm{C}$ by 14 process-based models in the permafrost regions. They suggested that the better structural representation of hydrological cycle and carbon dynamics may be improve the modeling of carbon in the permafrost region (Alton et al., 2007; Li et al., 2017).

Net primary production (NPP) is an important flux in the terrestrial carbon cycle, which could reflect the ability of plant absorbing atmospheric carbon dioxide $\left(\mathrm{CO}_{2}\right)$ concentration (Zhao and Running 2010; Sun and Mu, 2018). However, it is not clear that the response of the NPP to hydrological cycle. For example, Sakaguchi et al. (2011) indicated that the sensitivity of NPP to drought may be unreasonable due to the allometic relationship. In this study, the degree of uncertainties of simulated and 
predicted NPP will be evaluated due to the uncertainties of hydrological physical processes. An approach of conditional nonlinear optimal perturbation related to parameters (CNOP-P, Mu et al., 2010) is employed to solve the maximal extent of uncertainties of simulated and predicted NPP. This method has been used to explore the impact of climate change on NPP (Sun and Mu, 2018). There are few studies on the uncertainties in the physical parameters of NPP using the CNOP-P approach. In addition, the influence of modeled NPP on all parameters of the hydrological process will be explored. The benefits of reducing the parameters in hydrological processes to modeled soil carbon will also be explored.

\section{Model and methods}

\subsection{Lund-Potsdam-Jena Wetland Hydrology and Methane Dynamic Global} Vegetation Model (LPJ-WHyMe model)

The LPJ-WHyMe v1.3.1 model was developed by Wania et al. (2010) based on the Lund-Potsdam-Jena Dynamic Global Vegetation Model (LPJ, Sitch et al., 2003; Gerten et al., 2004) and the Lund-Potsdam-Jena Wetland Hydrology (LPJ-WHy, Wania et al., 2009a, b) model. The LPJ model is a developed earlier and state-of-the-art dynamics global vegetation model (DGVM) in the world. And, this model has been applied to discuss the terrestrial ecosystem, and climate effects (Hickler, et al., 2006; Beer et al., 2007; Sun and Mu, 2018), and also served IPCC reports to simulate and predict the terrestrial carbon cycle, and to study the interaction with the atmosphere (IPCC, 2013). The current LPJ-WHyMe model not only 
combines the advantages of the LPJ model, but also adds features, such as permafrost dynamics, peatland hydrology, and peatland vegetation, active layer depth, and freeze-thaw cycle, and so on. In this study, the NPP in Northern and Northeastern China, where seasonal frozen soil is located in, is discussed. The old version LPJ model fails to explore the dynamics of terrestrial carbon cycle due to variations of seasonal permafrost dynamics. However, the new version LPJ-WHyMe model completely considers the seasonal permafrost dynamics. The new version LPJ-WHyMe model could be employed to evaluate the terrestrial carbon cycle in seasonal frozen soil. In addition to, there are 12 plant functional types (PFTs) in this version of the model: tropical broadleaved evergreen (TrBE) tree, tropical broadleaved raingreen $(\mathrm{TrBR})$ tree, temperate needleleaved evergreen (TeNE) tree, temperate broadleaved evergreen $(\mathrm{TeBE})$ tree, temperate broadleaved summergreen (TeBS) tree, boreal needleleaved evergreen (BoNE) tree, boreal needleleaved summergreen (BoNS) tree, boreal broadleaved summergreen (BoBS) tree, C3 perennial grass (C3PG), C4 perennial grass (C4PG), flood tolerant $\mathrm{C} 3$ graminoid, and Sphagnum moss. Other important characteristics enable the simulation of hydrological cycles, especially for ice and snow simulation. The hydrological cycle not only includes how to describe soil hydrology, plant water balance, and daily canopy conductance but also how to calculate the states of water under different temperature conditions, such as the liquid and solid (i.e., snow, ice, and freeze-thaw cycle, respectively) states. Previous studies revealed that runoff and evapotranspiration computed by the LPJ model agreed well with respective results 
from state-of-the-art global hydrological models. Moreover, the different hydrological characteristics, such as water table position, annual evapotranspiration, and active layer depth, are consistent with the observations employing the LPJ-WHyMe model.

The hydrological processes in the LPJ-WHyMe model own the relationship between hydrological processes and terrestrial ecosystem, not including the processes with the ocean, reservoir, river and lake, and so on. The precipitation could reach the land through direct and indirect ways. In no plant, the precipitation will directly reach the land. However, if there is a plant, the plant firstly intercepts part of the precipitation. The total precipitation is intercepted, so there is no precipitation to the land. Moisture in the soil originates in precipitation of atmosphere, and reaches the deep soil through percolation. Moisture in the soil also will lost due to evaporation, surface runoff, and subsurface runoff, and so on. In permafrost region, moisture in the soil will undergo the freeze-thaw Cycle through the thermal properties of soils. The interaction between the hydrological processes and the plant could be depicted. The interaction between the two is reflected in the fact that the growth of vegetation requires the supply of soil moisture by the root, and the vegetation discharges moisture to atmosphere through transpiration.

\subsection{Determination of the sensitivity parameter based on the CNOP-P}

There are several parameters in hydrological processes. To find the subset of relatively sensitive parameters among all parameters in hydrological processes that impact the NPP, a sensitivity analysis based on the CNOP-P is employed. Compared 
to the sensitivity analysis based on the CNOP-P proposed by Sun and Mu (2017), the combined method will be directly implemented to identify the sensitivity of the parameter combination for all candidate parameters and will not execute the step of deleting some insensitivity parameters (Sun et al., 2017). The CNOP-P and its cost function will be calculated for the NPP. The sensitivities of every group of parameter combinations will be ranked according their cost function values. The larger the objective function value is, the stronger the sensitivity for all parameter combinations.

\section{Experimental designs}

To evaluate the impact of the hydrological process on the NPP, seven parameters related to the hydrological processes are chosen, including one parameter depending on the soil type and two parameters depending on the PFTs (Table S1, S2, and S3,

Zaehle et al., 2005). $g_{m}$ and $\alpha_{m}$ are employed to compute the demand of actual evapotranspiration (Eq. 1).

$$
d_{\text {emand }}=\left(1-w_{e t}\right) * p_{e t} * \alpha_{m} /\left(1+\left(g_{m} /\left(g_{p} / f_{p c}\right)\right)\right) * f_{p c}^{*} p_{h e n}
$$

$d_{\text {emand }}$ represents the demand of actual evapotranspiration, $w_{e t}$ is the fraction of the day when the canopy is wet, $p_{e t}$ is potential evapotranspiration, $g_{p}$ is non-water-stressed canopy conductance, $f_{p c}$ is foliage projective cover, and $p_{h e n}$ is phenology. $p_{t}$ and $i_{n t c}$ are used to calculate the PFT-specific interception loss (Eqs. 2 and 3$)$.

$$
\begin{aligned}
& i_{\text {ntstore }}=i_{n t c} * l_{a i} * p_{h e n} * p \\
& i_{n t e r c e p}=p_{e t} * p_{t} * w_{e t}
\end{aligned}
$$


$i_{n t s t o r e}$ is water stored in the canopy, $l_{a i}$ is the leaf area index (LAI), and $p$ is precipitation. $k_{1}$ and $k_{2}$ are applied to the percolation formula (Eq. 4).

$$
p_{e r c}=k_{1} * w_{1}^{k_{2}}
$$

$p_{\text {erc }}$ is the percolation, and $w_{1}$ is water content in the surface layer. $f_{1}$ is related to available water (Eq. 5).

$$
w_{r}=w_{1} * f_{1}+w_{2} *\left(1-f_{1}\right)
$$

$w_{2}$ is the water content of the root layer. Among the seven parameters, $k_{1}$ is related to the soil type (Table S2), and $i_{n t c}$ and $f_{1}$ are dependent on the PFTs (Table S3). According to climate conditions, we choose four study regions with different dry and wet conditions ( $\mathrm{Ma}$ and $\mathrm{Fu}, 2005$; Sun and $\mathrm{Mu}, 2018$ ). The four regions are $\mathrm{R} 1$ $\left(125.75^{\circ} \mathrm{E}-126.75^{\circ} \mathrm{E}, 45.75^{\circ} \mathrm{N}-46.75^{\circ} \mathrm{N}\right.$; semihumid region and seasonal frozen soil, Ran et al., 2012), R2 $\left(115.75^{\circ} \mathrm{E}-116.75^{\circ} \mathrm{E} ; 26.25^{\circ} \mathrm{N}-27.25^{\circ} \mathrm{N}\right.$; humid region and instantaneous frozen ground, Ran et al., 2012), R3 $\left(115.75^{\circ} \mathrm{E}-116.75^{\circ} \mathrm{E}\right.$, $32.25^{\circ} \mathrm{N}-33.25^{\circ} \mathrm{N}$; semihumid region and seasonal frozen soil, Ran et al., 2012), and $\mathrm{R} 4\left(115.75^{\circ} \mathrm{E}-116.75^{\circ} \mathrm{E}, 36.25^{\circ} \mathrm{N}-37.25^{\circ} \mathrm{N}\right.$; arid and semiarid region and seasonal frozen soil, Ran et al., 2012). In each study area (R1, R2, R3, and R4), there are $90.5^{\circ}$ $* 0.5^{\circ}$ grid points, which are corresponding to the resolution of the climate inputs. The PFTs are BoNM trees (BoNE and BoNS trees), TeBE trees, TeBS trees, and C3PG. The LPJ-WHyMe model was run to supply the initial condition for 1000 years using the new Climatic Research Unit (CRU) data (Harris et al., 2014; https://crudata.uea.ac.uk/cru/data/hrg/), which include monthly air temperature (degrees Celsius), monthly cloud cover (\%), monthly wet day frequency (days) and 
monthly precipitation $(\mathrm{mm})$, with a $0.5^{\circ}$ resolution (latitude/longitude), which has been popularly applied to study the terrestrial ecosystem and carbon cycle, for all land areas (excluding Antarctica). The model is run over 1000 years. The last 100 years are the optimization period, and the average of soil carbon during the last fifty years of the optimization period is regarded as the target.

These seven physical parameters have different magnitudes and ranges; therefore, the physical parameters should be normalized according to study of Sun and $\mathrm{Mu}$ (2017). The standardization formula is as follows:

$$
\left\{\begin{array}{l}
y=\frac{x-\text { Defvalue }}{\text { Maxvalue }- \text { Defvalue }}, \\
y=\frac{x-\text { Defvalue }}{\text { Defvalue }- \text { Minvalue }}, \quad \text { when } x<\text { Defvalue }
\end{array} .\right.
$$

Here, $x$ and $y$ are the prenormalization and postnormalization parameters, respectively. Defvalue, Maxvalue, and Minvalue are the standard, maximum and minimum values of the parameters, respectively. In this study, the normalized parameters are controlled by the lower and upper bounds $([-1,1])$.

To evaluate which parameters are relatively sensitive and important among all hydrological parameters, $C_{7}^{i}(i=1,2,3,4,5,6)$ groups of optimization experiments are conducted to obtain the CNOP-P and its cost function. Hence, $126\left(\sum_{i=1}^{6} C_{7}^{i}=126\right)$ groups of optimization experiments are calculated. For each $C_{7}^{i}(i=1,2,3,4,5,6)$, the parameter combination corresponding to the maximal cost function among $C_{7}^{i}$ experiments is considered as the relatively sensitive parameter combination. To obtain the optimal values (CNOP-P), the differential evolution (DE; Storn and Price, 1997) 
algorithm is employed. Fifty groups of random samples are applied to the DE algorithm to obtain the optimal values. The optimal value that causes the maximal cost function is chosen among the fifty optimal values. Ten small-magnitude random samples are superimposed on the optimal value to check the peak of the constrained optimization problem. The above process is repeated to finally obtain the optimal value without a local optimal value.

\section{Results and analysis}

\subsection{Uncertainties in NPP simulation caused by errors in all hydrological parameters}

Firstly, the simulated NPP is shown without the errors of hydrological physical parameters. It is shown that the NPP in arid and semi-arid region of Northern China is from 397.9 to $423.7 \mathrm{~g} \mathrm{C} \mathrm{m}^{-2}$ year $^{-1}$, and is smallest among all study regions, which is 409. $1 \mathrm{~g} \mathrm{C} \mathrm{m}^{-2}$ year $^{-1}$ for spatial average. In the Southern China, the NPP is from 538.1 to $595.8 \mathrm{~g} \mathrm{C} \mathrm{m}^{-2}$ year $^{-1}$, and is largest among all study regions, which is $409.1 \mathrm{~g} \mathrm{C} \mathrm{m}^{-2}$ year $^{-1}$ for spatial average. The simulated NPPs of spatial average are 461.4 and 487.2 $\mathrm{g} \mathrm{C} \mathrm{m}^{-2}$ year $^{-1}$ in Northeastern China and Northern China with semi-humid climate condition.

Secondly, effects of errors of hydrological physical parameters on the simulated NPP are quantified in different study regions (Figure 1). In terms of relative error and absolute error, the largest simulation or prediction error of the NPP occurs in arid and semi-arid region of Northern China, which are $48.6 \%$ and $198.5 \mathrm{~g} \mathrm{C} \mathrm{m}^{-2}$ year $^{-1}$. 
However, in the Northern China with semi-humid climate condition, the relative error and absolute error are the smallest for the simulation or prediction error of the NPP, which are $13.2 \%$ and $64.4 \mathrm{~g} \mathrm{C} \mathrm{m}^{-2}$ year ${ }^{-1}$. The relative error and absolute error in Southern and Northeastern China are between the above two, which are 21.1\% (117.0 $\mathrm{g} \mathrm{C} \mathrm{m}^{-2}$ year $\left.^{-1}\right)$, and $19.1 \%\left(88.4 \mathrm{~g} \mathrm{C} \mathrm{m}^{-2}\right.$ year $\left.^{-1}\right)$.

Uncertainties of the hydrological physical parameters could bring into large simulation and prediction error for the NPP. To study the benefits of modeling NPP when reducing the hydrological parameter errors, an experiment is implemented as follows:

$$
\tau=\frac{\left\|M_{T}\left(\boldsymbol{U}_{0}, \boldsymbol{P}+\boldsymbol{p}\right)-M_{T}\left(\boldsymbol{U}_{0}, \boldsymbol{P}\right)\right\|-\left\|M_{T}\left(\boldsymbol{U}_{0}, \boldsymbol{P}+(1-\alpha) \boldsymbol{p}\right)-M_{T}\left(\boldsymbol{U}_{0}, \boldsymbol{P}\right)\right\|}{\left\|M_{T}\left(\boldsymbol{U}_{0}, \boldsymbol{P}+\boldsymbol{p}\right)-M_{T}\left(\boldsymbol{U}_{0}, \boldsymbol{P}\right)\right\|}
$$

$\tau$ represents the benefit of modeling NPP when reducing the hydrological parameter errors. The larger $\tau$ is, the better the improvement in the NPP simulation. $P$ is the reference state of all hydrological parameters. $p$ is the CNOP-P related to all hydrological parameter errors. $\alpha \quad(=0.2,0.4,0.6$, and 0.8$)$ represents the extent of the error reduction in the correct parameters due to data assimilation or observation. The benefit of modeling NPP is improved, and it increases with the increase in $\alpha$ for the studied cases (Figure 2). It is found that the benefits of the simulated NPP will increase with the augment of $\alpha$ for each case. When $\alpha=0.2,0.4,0.6$, and 0.8 , the benefits of the simulated NPP are $0.04,0.08,0.15$, and 0.29 for the whole study region. However, the benefits of NPP modeling are different for the four regions of China due to reducing the CNOP-P-type parameter error. In Southern China, the benefits are highest compared other three study regions. The benefits of the simulated 
NPP are $0.15,0.28,0.39$, and 0.48 when $\alpha=0.2,0.4,0.6$, and 0.8 . The benefits of the simulated NPP are lowest in Northern China under semi-humid climate conditions, and are $0.001,0.004,0.011$, and 0.030 when $\alpha=0.2,0.4,0.6$, and 0.8 . The benefits of the simulated NPP are 0.01, 0.03, 0.11, and 0.29 in Northeastern China, and 0.002, 0.02, 0.08, and 0.35 in Northern China under arid and semi-arid climate conditions when $\alpha=0.2,0.4,0.6$, and 0.8 .

\subsection{The sensitive parameter subset among all hydrological parameters for NPP modeling}

Within the LPJ-WHyMe model, the hydrological physical processes include many processes, such as interception loss, transpiration, evaporation, snowmelt, permafrost and so on. To find which hydrological physical processes are relatively important for the NPP simulation, a sensitivity analysis for all hydrological parameters is carried out to judge the relatively sensitive parameter subset. The subset with relatively sensitive parameters with arbitrary numbers is determined using the CNOP-P approach. For example, $35\left(C_{7}^{3}=35\right)$ groups of experiments are computed using the CNOP-P approach if the number of relatively sensitive parameters in the subset is 3. Among the 35 parameter combinations, the parameter subset corresponding to the maximal cost function is regarded as the relatively sensitive

parameter combination. Hence, $126\left(\sum_{i=1}^{6} C_{7}^{i}=126\right)$ groups of tests are executed to identify the relatively sensitive parameter combination. Table 1 shows the relatively sensitive parameter subset. The relatively sensitive parameter subsets of any number 
are different for the four study regions. It is found that $g_{m}$, which represents maximum canopy conductance analog, is important to the NPP simulation compared to other six parameters for all study region. In the Northern China with arid and semi-arid climate conditions, evapotranspiration parameter $\alpha_{m}$ will also be important parameter combined with $g_{m}$. It is imply that the evaporation is important in the water-limited region. In the Southern China with high temperature climate conditions, evapotranspiration parameter $\alpha_{m}$ will also be important parameter combined with $g_{m}$. With the increase of number of parameter subset, evapotranspiration parameter $\alpha_{m}$ will be unimportant in the Southern China. Due to the abundance precipitation, the percolation and root uptaking water from the topsoil layer are important. In the Northern China with arid and semi-arid climate condition, the root uptaking water from the topsoil layer is important, which implies that the transpiration is important in the water-limited regions.

The sensitivity parameter subset is identified in different regions. The corresponding simulation or prediction error is also shown (Figure 3). We found that the simulation or prediction error of the NPP gradually increase with the augment of the number of sensitive parameters for all study regions. However, the increasing extent of the simulation or prediction error decreases. For most cases, the simulation or prediction error due to five sensitive parameter subset is comparable to that due to all hydrological parameters. It is implied that the simulation or prediction error is saturated. For example, in the Southern China, the simulation error of the NPP is $4.3 \mathrm{~g}$ $\mathrm{C} \mathrm{m}^{-2}$ year $^{-1}$ due to the most sensitive one hydrological parameter, but that is $117.0 \mathrm{~g}$ 
$\mathrm{C} \mathrm{m}^{-2}$ year $^{-1}$ due to the all hydrological parameters, and that is $113.5 \mathrm{~g} \mathrm{C} \mathrm{m}^{-2}$ year $^{-1}$ due to the most sensitive five hydrological parameters. However, in the Northern China with arid and semi-arid climate conditions, the simulation error of the NPP due to the most sensitive one hydrological parameter is close to that due to the all hydrological parameters, and is $193.9 \mathrm{~g} \mathrm{C} \mathrm{m}^{-2}$ year $^{-1}$ and $198.5 \mathrm{~g} \mathrm{C} \mathrm{m}^{-2}$ year $^{-1}$. The above numerical results demonstrate that the relatively sensitive parameter subsets could represent the all hydrological processes. The numerical results provide an evidence for reducing errors in a small number of parameters to improve the ability of the simulated NPP. On the other hand, the most sensitive one hydrological parameter to be reduced to improve the ability of simulated NPP is sufficient in the Northern China under arid and semi-arid climate condition.

\section{Conclusions and discussions}

In this study, the effects of hydrological processes on modeling NPP in four different study regions under wet and arid conditions in China are assessed. Using the CNOP-P approach, we found that the error of NPP simulation or prediction is $198.5 \mathrm{~g}$ $\mathrm{C} \mathrm{m}^{-2} \mathrm{yr}^{-1}(48.6 \%)$ in the arid and semiarid region of northern China due to the uncertainties in the hydrological processes, which is greater than other three regions. Among all hydrological processes, the water content in the soil surface layer may play an key role in the arid and semiarid region of northern China, because the error of the water content is $27 \%$ (volumetric soil water content), which is greater than those in other three regions. The water content in soil surface layer is a necessary condition to 
growth of the plant. The variation of the plant will directly cause the change of terrestrial carbon cycle, such as NPP. Evapotranspiration $(-179.08 \mathrm{~mm} /$ year $)$ and runoff $(166.01 \mathrm{~mm})$ may play a secondary role in the arid and semiarid region of northern China. The errors of NPP simulation or prediction are $88.4 \mathrm{~g} \mathrm{C} \mathrm{m}^{-2} \mathrm{yr}^{-1}$ (19.1\%) in northeastern China, $117.0 \mathrm{~g} \mathrm{C} \mathrm{m}^{-2} \mathrm{yr}^{-1}$ (21.1\%) in southern China, and 64.4 $\mathrm{g} \mathrm{C} \mathrm{m}^{-2} \mathrm{yr}^{-1}(13.2 \%)$ in the semi-humid region of northern China. In the semi-humid region of northern China, the character is completely opposite to that in the arid and semiarid region of northern China. Evapotranspiration (-278.44 $\mathrm{mm} /$ year) and runoff $(257.36 \mathrm{~mm})$ may play a main role, while the water content $(23 \%)$ in the soil surface layer is second. In the remaining two areas, three hydrological processes play a considerable role. In agreement with our findings, Huang et al. (2016) mostly found variations in simulated NPP were sensitive to drought. The above studies and our work deduced that the uncertainties in hydrological processes will result in large errors in soil carbon modeling. Regardless of the role of the three hydrological processes, they all play an important role in plant growth and terrestrial carbon cycle. In the terrestrial ecosystem, the precipitation is the source of the hydrological processes. Part of precipitation is intercepted by leaf of vegetation, and most of it is diverted in the form of soil moisture and runoff. The soil moisture supplies the growth of plants by the root. Through the process of evapotranspiration, the water of the plant diffuses into the atmosphere, and eventually forming the interaction between carbon cycle and hydrological processes.

The numerical results imply that NPP modeling or prediction may be improved by 
reducing the errors in the hydrological parameters. A sensitivity analysis was also employed to find those parameters among all hydrological parameters that could cause much more simulation or prediction errors in NPP. The relatively sensitive parameter subsets with any number of parameters are different for the four study regions. The numerical results imply that it is necessary to find the relatively sensitive parameter subsets among all hydrological processes. The relatively sensitive parameter subsets should be preferentially observed or optimized in numerical models to enhance the predictions of soil carbon and carbon-climate feedback.

Compared to the LPJ model, the characters of the LPJ-WhyMe are permafrost dynamics, peatland hydrology, and peatland vegetation, active layer depth, and freeze-thaw cycle, and so on. In this study, most regions are located on the seasonal frozen soil. It is suitable to employ the LPJ-WHyMe model to evaluate the variations of NPP to Hydrological dynamics, especially in the seasonal frozen soil. It is worth noting that there is the seasonal frozen soil in our study regions. The target period is 100 years for our study to explore the climatic characteristics of the annual NPP. The variabilities of permafrost, active layer depth, freeze-thaw cycle, groundwater in seasonal frozen soil are visible, but the climatic characteristics of the seasonal frozen soil are dim. In the future, seasonable characteristics of permafrost, active layer depth, freeze-thaw cycle, groundwater should be discussed to probe the seasonal terrestrial carbon cycle. 
Acknowledgments and funding. Funding was provided by grants from the National Key Research and Development Program of China (No. 2016YFA0600804) and the National Natural Science Foundation of China (Nos. 41675104, 41975132).

\section{Availability of data and materials}

The research data of this study can be obtained upon by requesting the corresponding author.

\section{Competing interests}

The authors declare that they have no conflict of interests.

\section{Authors' contributions}

MU Mu provided supervision for this study, and checked/corrected all the versions of the manuscript. Guodong Sun conducted experiments and data analyses, and prepared for the manuscript. All authors read and approved the final manuscript. 
Appendix

Introduction of the conditional nonlinear optimal perturbation related to parameters $(C N O P-P)$

Here, we present the details of this method for the reader's convenience. Let the state variable $\boldsymbol{U}$ be the solution to the following equations:

$$
\left\{\begin{array}{l}
\frac{\partial \boldsymbol{U}}{\partial t}=F(\boldsymbol{U}, \boldsymbol{P}) \quad \boldsymbol{U} \in R^{n}, t \in[0, T] \\
\left.\boldsymbol{U}\right|_{t=0}=\boldsymbol{U}_{0}
\end{array}\right.
$$

where $\boldsymbol{U}_{0}$ is an initial value of the state variable $\boldsymbol{U}, F$ is a nonlinear partial differential operator, and $\boldsymbol{P}$ is the equation parameter. $M_{\tau}$ is the propagator of Eq. 1 above from the initial time 0 to $\tau$. Then, $\boldsymbol{U}(\tau)=M_{\tau}\left(\boldsymbol{U}_{0}, \boldsymbol{P}\right)$. The solution of Eq. 1, which is determined by the parameter perturbation, $\boldsymbol{p}$, is $M_{\tau}\left(\boldsymbol{U}_{0}, \boldsymbol{P}+\boldsymbol{p}\right)$. The difference between the reference state $\boldsymbol{U}(\tau)$ and the $\boldsymbol{U}(\tau)+\boldsymbol{u}(\tau)$ induced by $\boldsymbol{p}$ is described by $\boldsymbol{u}(\tau)$.

For an optimal time, $T$, and norm, $\|\cdot\|$, the perturbation $\boldsymbol{p}_{\delta}$ is regarded as the CNOP-P under the constraining condition $\boldsymbol{p} \in \Omega$ if and only if,

$$
J\left(\boldsymbol{p}_{\delta}\right)=\max _{p \in \Omega} J(\boldsymbol{p})
$$

where

$$
J(\boldsymbol{p})=\|\boldsymbol{u}(T)\|=\left\|M_{T}\left(\boldsymbol{U}_{0}, \boldsymbol{P}+\boldsymbol{p}\right)-M_{T}\left(\boldsymbol{U}_{0}, \boldsymbol{P}\right)\right\| .
$$

$\Omega$ is the constraint domain. From the above optimization problem, the CNOP-P represents a type of parameter error that can trigger the upper boundary of the simulation and the prediction error due to the parameter error. 


\section{References:}

Alton, P., L. Mercado, and P. North (2007), A sensitivity analysis of the land-surface scheme JULES conducted for three forest biomes: Biophysical parameters, model processes, and meteorological driving data, Global Biogeochem. Cycles, 20, GB1008, doi:10.1029/2005GB002653.

Anav, A., P. Friedlingstein, M. Kidston, L. Bopp, P. Ciais, P. Cox, C. Jones, M. Jung, R. Myneni, and Z. Zhu (2013), Evaluating the land and ocean components of the global carbon cycle in the CMIP5 Earth system models, J. Clim., 26(18), 6801-6843.

Baker, I. T., L. Prihodko, A. S. Denning, M. Goulden, S. Miller, and H. R. da Rocha (2008), Seasonal drought stress in the Amazon: Reconciling models and observations, J. Geophys. Res., 113, G00B01, doi:10.1029/2007JG000644.

Bao, R., van der Voort, T. S., Zhao, M., Guo, X., Montluçon, D. B., McIntyre, C., \& Eglinton, T. I. (2018). Influence of hydrodynamic processes on the fate of sedimentary organic matter on continental margins. Global Biogeochemical Cycles, 32, 1420-1432. https://doi.org/10.1029/2018GB005921

Beer, C., W. Lucht, D. Gerten, K. Thonicke, and C. Schmullius (2007), Effects of soil freezing and thawing on vegetation carbon density in Siberia: A modeling analysis with the Lund-Potsdam-Jena Dynamic Global Vegetation Model (LPJ-DGVM), Global Biogeochem. Cycles, 21, GB1012, doi:10.1029/2006GB002760.

Gerten, D., S. Schaphoff, U. Haberlandt, W. Lucht, and S. Sitch. 2004. Terrestrial vegetation and water balance: hydrological evaluation of a dynamic global vegetation model. J. Hydrol., 286: 249-270. doi:10.1016/j.jhydrol.2003.09.029

Gurney, K. R., and W. J. Eckels (2011), Regional trends in terrestrial carbon exchange and their seasonal signatures, Tellus Ser. B, 63, 328-339.

Harris, I., Jones, P.D., Osborn, T.J. and Lister, D.H. (2014), Updated high-resolution grids of monthly climatic observations - the CRU TS3.10 Dataset. International Journal of Climatology 34, 623-642 doi:10.1002/joc.3711

Heimann, M., and M. Reichstein (2008), Terrestrial ecosystem carbon dynamics and climate feedbacks, Nature, 451, 289-292.

Hickler, T., Prentice, I.C., Smith, B., Sykes, M.T. and Zaehle, S. (2006), Implementing plant hydraulic architecture within the LPJ Dynamic Global Vegetation Model. Global Ecology and Biogeography, 15: 567-577. doi:10.1111/j.1466-8238.2006.00254.x

Huang, Y., S. Gerber, T. Huang, and J. W. Lichstein (2016), Evaluating the drought response of CMIP5 models using global gross primary productivity, leaf area, precipitation, and soil moisture data, Global Biogeochem. Cycles, 30, 1827-1846, doi:10.1002/ 2016GB005480. 
IPCC, 2013: Climate Change 2013: The Physical Science Basis. Contribution of Working Group I to the Fifth Assessment Report of the Intergovernmental Panel on Climate Change [Stocker, T.F., D. Qin, G.-K. Plattner, M. Tignor, S.K. Allen, J. Boschung, A. Nauels, Y. Xia, V. Bex and P.M. Midgley (eds.)]. Cambridge University Press, Cambridge, United Kingdom and New York, NY, USA, 1535 pp.

Li, Y., H. Yang, T. Wang, N. MacBean, C. Bacour, P. Ciais, Y. Zhang, G. Zhou, and S. Piao (2017), Reducing the uncertainty of parameters controlling seasonal carbon and water fluxes in Chinese forests and its implication for simulated climate sensitivities, Global Biogeochem. Cycles, 31, 1344-1366, doi:10.1002/ 2017GB005714.

Luo Yiqi, Trevor F. Keenan, Matthew Smith. 2015. Predictability of the terrestrial carbon cycle. Global Change Biology, 21, 1737-1751, doi: 10.1111/gcb.12766.

Ma, Z. G., and C. B. Fu. 2005. "Decadal variations of arid and semi-arid boundary in China." Chinese Journal of Geophysics 48: 519-525.

McGuire, A. D., et al. (2016), Variability in the sensitivity among model simulations of permafrost and carbon dynamics in the permafrost region between 1960 and 2009, Global Biogeochem. Cycles, 30, 1015-1037, doi:10.1002/2016GB005405.

Mu, M., W. Duan, Q. Wang, and R. Zhang (2010), An extension of conditional nonlinear optimal perturbation approach and its applications, Nonlin. Processes Geophys., 17(2), 211-220.

Ran YH, Li X, Cheng GD, Zhang TJ, Wu QB, Jin HJ, Jin R (2012) Distribution of permafrost in China: an overview of existing permafrost maps. Permafrost Periglacial Process 23:322-333

Sakaguchi, K., X. Zeng, B. J. Christoffersen, N. Restrepo - Coupe, S. R. Saleska, and P. M. Brando (2011), Natural and drought scenarios in an east central Amazon forest: Fidelity of the Community Land Model 3.5 with three biogeochemical models, J. Geophys. Res., 116, G01029, doi:10.1029/2010JG001477.

Schwalm, C. R., C. A. Williams, and K. Schaefer (2011), Carbon consequences of global hydrologic change, 1948-2009, J. Geophys. Res., 116, G03042, doi:10.1029/2011JG001674.

Scott-Denton, L. E., D. J. P. Moore, N. A. Rosenbloom, T. G. F. Kittel, S. P. Burns, D. S. Schimel, and R. K. Monson (2013), Forecasting net ecosystem CO2 exchange in a subalpine forest using model data assimilation combined with simulated climate and weather generation, J. Geophys. Res. Biogeosci., 118, 549-565, doi:10.1002/jgrg.20039.

Sitch, S., B. Smith, I.C. Prentice, A. Arneth, A. Bondeau, W. Cramer, J. O. Kaplan, S. Levis, W. Lucht, M. T. Sykes, K. Thonicke, and S. Venevsky. 2003. Evaluation of ecosystem dynamics, plant geography, and terrestrial carbon cycling in the LPJ dynamic global vegetation model. Global Change Biology 9: 161-185. doi:10.1046/j.1365-2486.2003.00569.x 
Storn R, Price K (1997) Differential evolution - a simple and efficient heuristic for global optimization over continuous spaces. J. Global Optim. 11:341-359

Sun, G. D., and M. Mu, 2017: A new approach to identify the sensitivity and importance of physical parameters combination within numerical models, using the Lund-Potsdam-Jena (LPJ) model as an example. Theoretical and Applied Climatology, 128: 587-601, DOI: 10.1007/s00704-015-1690-9

Sun, G. D., F. Peng, and M. Mu, 2017.Uncertainty assessment and sensitivity analysis of soil moisture based on model parameters-results from four regions in China. Journal of Hydrology, 555: 347-360, DOI: 10.1016/j.jhydrol.2017.09.059

Sun, G. D., and M. Mu, 2018. Assessing the characteristics of net primary production due to future climate change and CO2 under RCP4.5 in China. Ecological Complexity, 34: 58-68.

Vicente-Serrano, S. M., et al. (2013), Response of vegetation to drought time-scales across global land biomes, Proc. Natl. Acad. Sci. U.S.A., 110(1), 52-57.

Wania, R., I. Ross, and I.C. Prentice. 2009a. Integrating peatlands and permafrost into a dynamic global vegetation model: 1. Evaluation and sensitivity of physical land surface processes. Global Biogeochem. Cycles 23: GB3014. doi:10.1029/2008GB003412

Wania, R., I. Ross, and I.C. Prentice. 2009b. Integrating peatlands and permafrost into a dynamic global vegetation model: 2. Evaluation and sensitivity of vegetation and carbon cycle processes. Global Biogeochem. Cycles 23: GB3015. doi:10.1029/2008GB003413

Wania, R., I. Ross, and I.C. Prentice. 2010. Implementation and evaluation of a new methane model within a dynamic global vegetation model: LPJ-WHyMe v1.3.1. Geosci. Model Dev. 3: 565-584. doi:10.5194/gmd-3-565-2010

Yu G R, Song X, Wang Q F et al., 2008. Water-use efficiency of forest ecosystems in eastern China and its relations to climatic variables. New Phytologist, 177(4): 927-937.

Zaehle S, Sitch S, Smith B, Hatterman F. 2005. Effects of parameter uncertainties on the modeling of terrestrial biosphere dynamics. Global Biogeochem. Cycles 19: GB3020, doi:10.1029/2004GB002395.

Zhao, M., and S. W. Running (2010), Drought-induced reduction in global terrestrial net primary production from 2000 through 2009, Science, 329(5994), 940-943. 

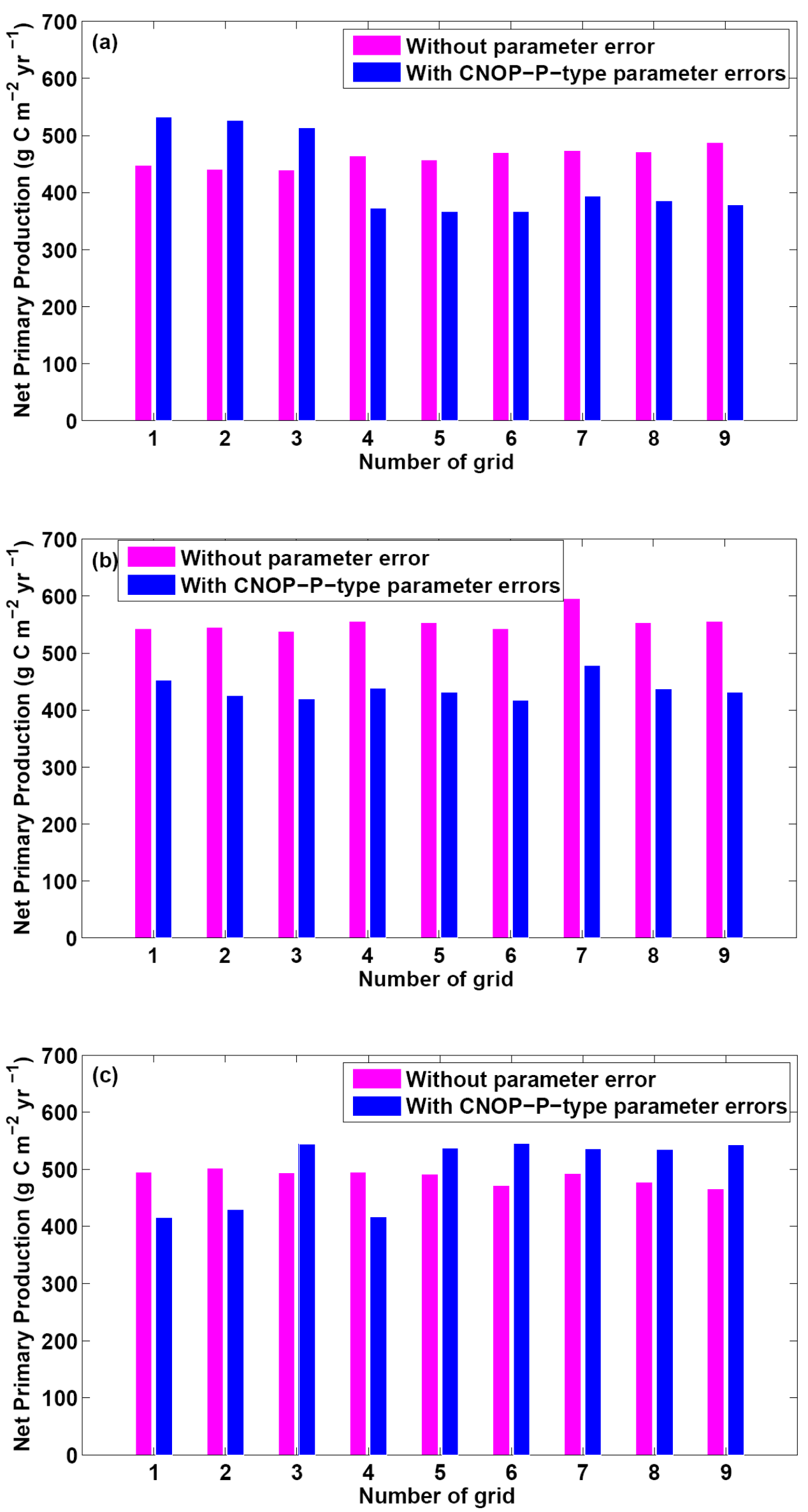


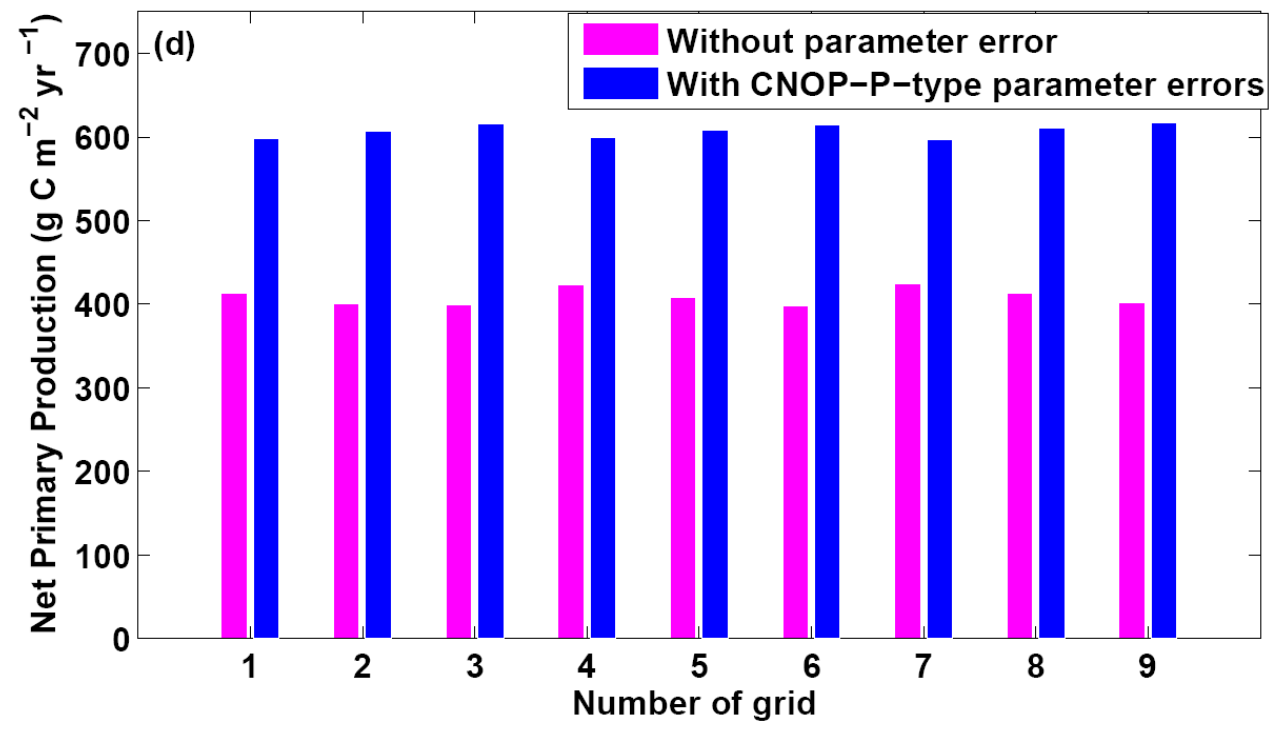

Figure 1 The modeled NPP without parameter errors and with the CNOP-P-type parameter errors for all hydrological parameters. (a): Northeastern China, (b): southern China, (c): northern China under semi-humid climate conditions, and (d): northern China under arid and semiarid climate conditions. 

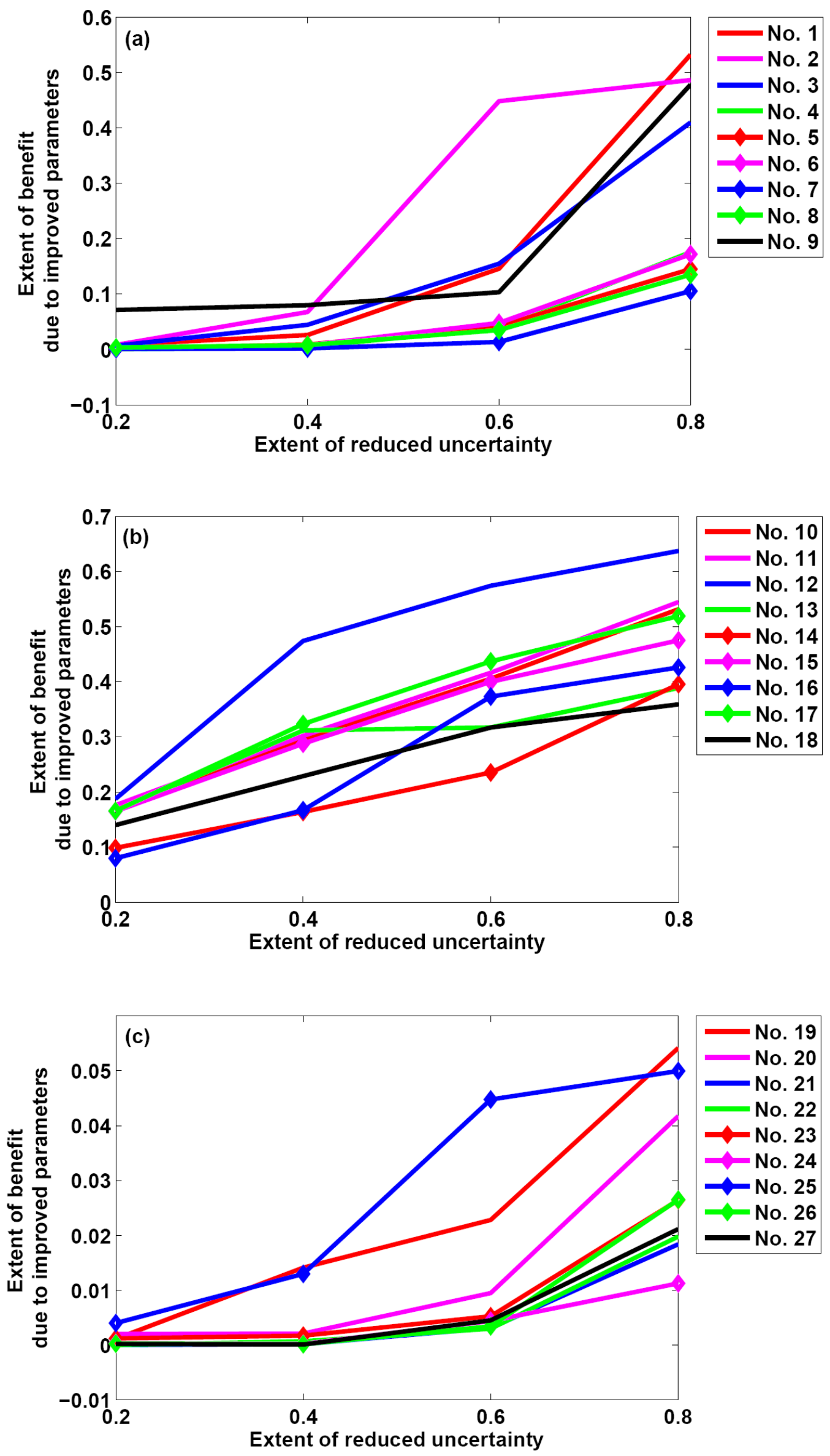


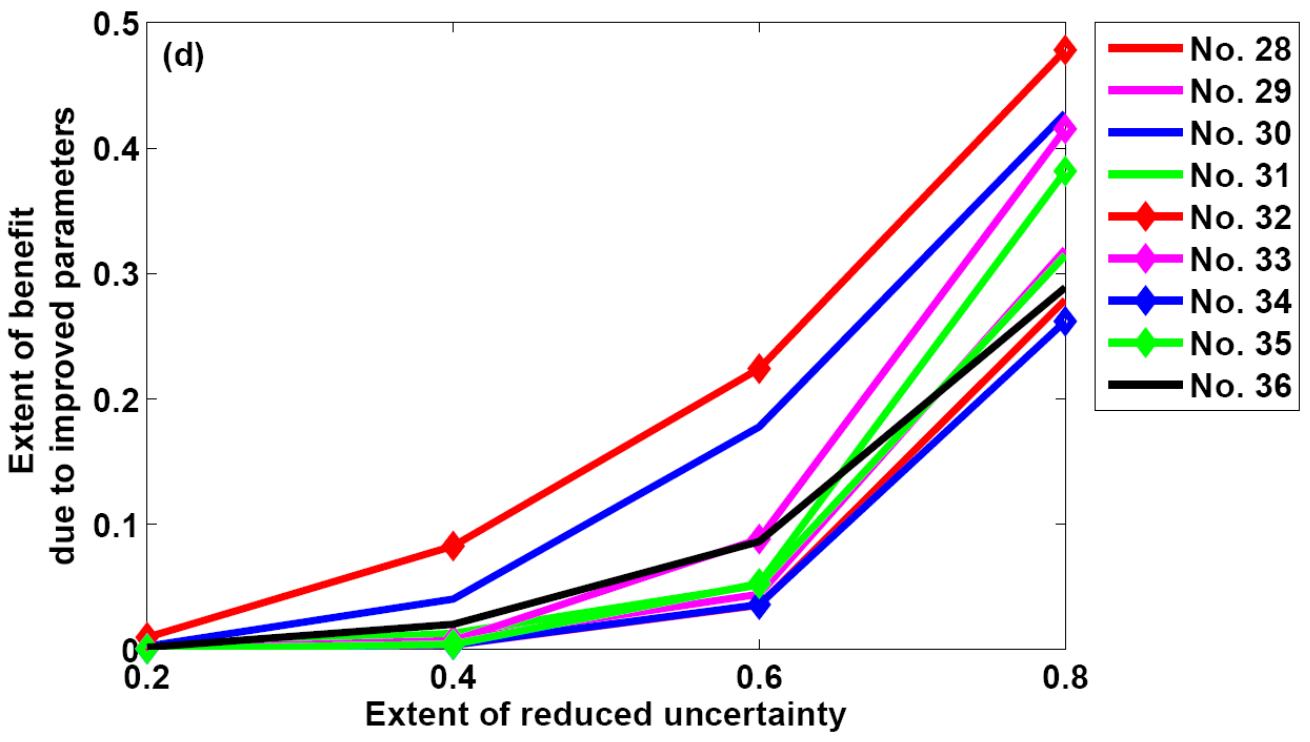

Figure 2 The benefit of modeled NPP by reducing the errors in the hydrological parameters. (a): Northeastern China, (b): southern China, (c): northern China under semi-humid climate conditions, and (d): northern China under arid and semiarid climate conditions. 

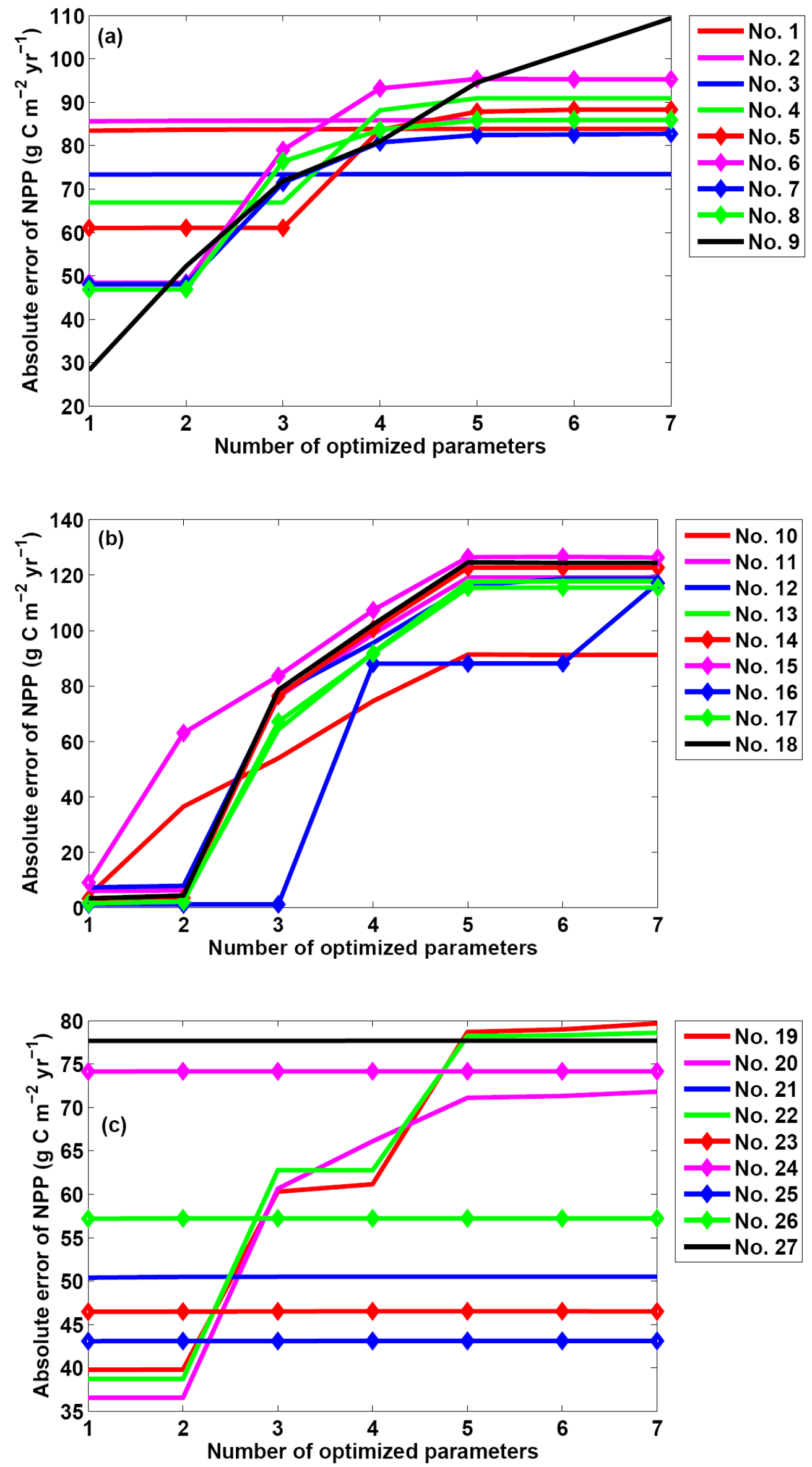


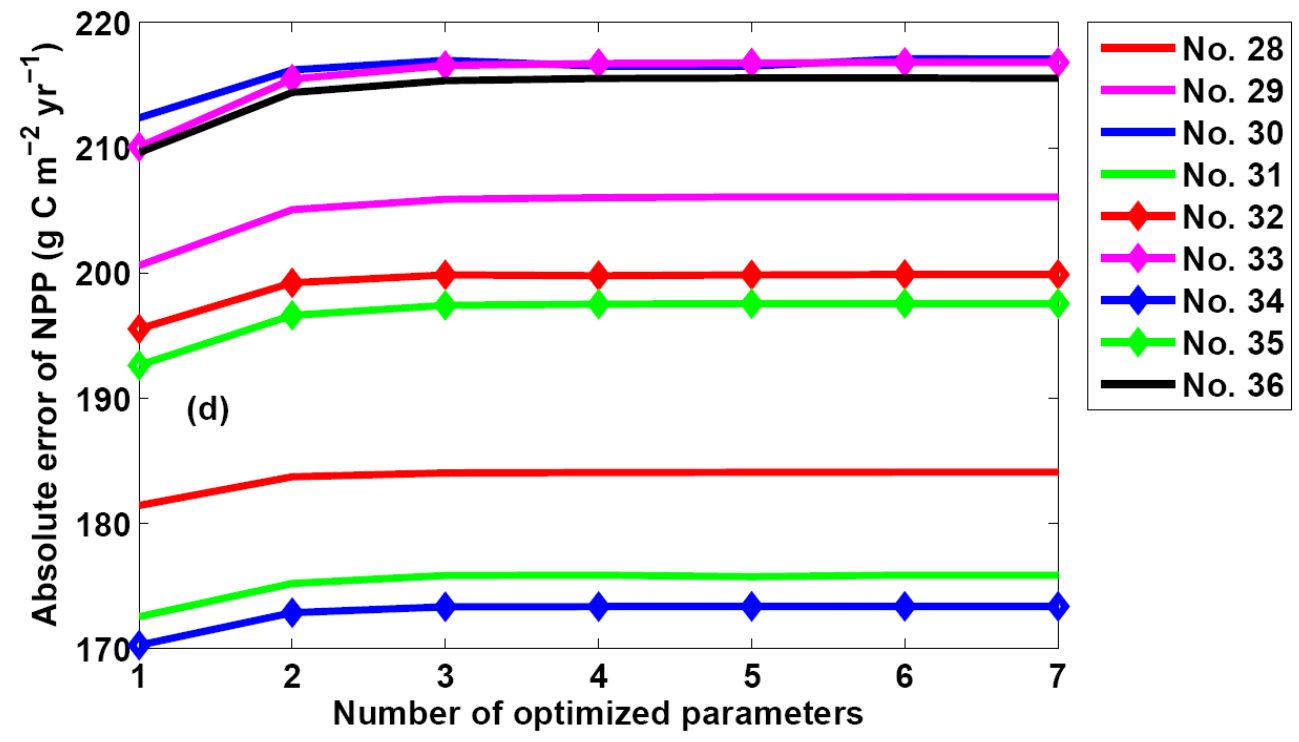

Figure 3 The errors in modeled NPP when different sizes of subsets are used for all hydrological parameters. (a): Northeastern China, (b): southern China, (c): northern China under semi-wet climate conditions, and (d): northern China under arid and semiarid climate conditions. 
Table 1 The identified subsets with one to six relatively sensitive parameters

\begin{tabular}{|c|c|c|c|c|c|c|}
\hline Location & $\begin{array}{l}\text { Parameter } \\
\text { combination }\end{array}$ & $\begin{array}{l}\text { Parameter } \\
\text { combination }\end{array}$ & $\begin{array}{l}\text { Parameter } \\
\text { combination }\end{array}$ & $\begin{array}{l}\text { Parameter } \\
\text { combination }\end{array}$ & $\begin{array}{l}\text { Parameter } \\
\text { combination }\end{array}$ & $\begin{array}{l}\text { Parameter } \\
\text { combination }\end{array}$ \\
\hline & $\begin{array}{l}\text { with one } \\
\text { parameter }\end{array}$ & $\begin{array}{l}\text { with two } \\
\text { parameters }\end{array}$ & $\begin{array}{l}\text { with three } \\
\text { parameters }\end{array}$ & $\begin{array}{l}\text { with four } \\
\text { parameters }\end{array}$ & $\begin{array}{l}\text { with five } \\
\text { parameters }\end{array}$ & $\begin{array}{l}\text { with six } \\
\text { parameters }\end{array}$ \\
\hline 125.75 & 1 & 1,7 & $1,6,7$ & $1,2,3,7$ & $1,2,3,4,7$ & $1,2,3,4,6,7$ \\
\hline \multicolumn{7}{|l|}{45.75} \\
\hline 125.75 & 1 & 1,6 & $1,6,7$ & $1,2,3,7$ & $1,3,4,6,7$ & $1,2,3,4,6,7$ \\
\hline \multicolumn{7}{|l|}{46.25} \\
\hline 125.75 & 1 & 1,7 & $1,6,7$ & $1,2,3,7$ & $1,3,4,6,7$ & $1,2,3,4,6,7$ \\
\hline \multicolumn{7}{|l|}{46.75} \\
\hline 126.25 & 1 & 1,7 & $1,2,7$ & $1,4,6,7$ & $1,3,4,6,7$ & $1,3,4,5,6,7$ \\
\hline \multicolumn{7}{|l|}{45.75} \\
\hline 126.25 & 1 & 1,7 & $1,5,7$ & $1,4,6,7$ & $1,3,4,6,7$ & $1,3,4,5,6,7$ \\
\hline \multicolumn{7}{|l|}{46.25} \\
\hline 126.25 & 1 & 1,6 & $1,4,6$ & $1,2,4,6$ & $1,3,4,6,7$ & $1,3,4,5,6,7$ \\
\hline \multicolumn{7}{|l|}{46.75} \\
\hline 126.75 & 1 & 1,7 & $1,4,6$ & $1,3,4,6$ & $1,3,4,5,6$ & $1,3,4,5,6,7$ \\
\hline \multicolumn{7}{|l|}{45.75} \\
\hline 126.75 & 1 & 1,7 & $1,4,6$ & $1,3,4,6$ & $1,3,4,6,7$ & $1,3,4,5,6,7$ \\
\hline \multicolumn{7}{|l|}{46.25} \\
\hline 126.75 & 1 & 2,6 & $1,2,6$ & $1,3,4,6$ & $1,2,4,6,7$ & $1,2,3,5,6,7$ \\
\hline \multicolumn{7}{|l|}{46.75} \\
\hline 115.75 & 1 & 4,6 & $1,4,6$ & $1,4,6,7$ & $, 2,4,6,7$ & $1,2,3,4,6,7$ \\
\hline \multicolumn{7}{|l|}{26.25} \\
\hline 115.75 & 1 & 1,2 & $1,4,6$ & $1,4,6,7$ & $1,2,4,6,7$ & $1,2,3,4,6,7$ \\
\hline \multicolumn{7}{|l|}{26.75} \\
\hline 115.75 & 1 & 1,2 & $1,4,6$ & $1,4,6,7$ & $1,2,4,6,7$ & $1,2,4,5,6,7$ \\
\hline \multicolumn{7}{|l|}{27.25} \\
\hline 116.25 & 1 & 1,2 & $1,4,6$ & $1,4,6,7$ & $1,2,4,6,7$ & $1,2,3,4,6,7$ \\
\hline
\end{tabular}


26.25

116.2

1,2

$1,4,6$

$1,4,6,7$

$1,2,4,6,7$

$1,2,3,4,6,7$

26.75

116.25

4,6

$1,4,6$

$1,4,6,7$

$1,2,4,6,7$

$1,2,3,4,6,7$

27.25

116.75

1,2

$1,2,3$

$1,4,6,7$

$1,3,4,6,7$

$1,3,4,5,6,7$

26.25

116.75

1,2

$1,4,6$

$1,4,6,7$

$1,2,4,6,7$

$1,2,3,4,6,7$

26.75

116.75

1,2

$1,4,6$

$1,4,6,7$

$1,2,4,6,7$

$1,2,3,4,6,7$

27.25

115.75

1,6

$4,6,7$

$3,4,6,7$

$2,4,5,6,7$

$1,2,4,5,6,7$

32.25

115.75

1,6

$2,4,6$

$1,3,4,6$

$2,4,5,6,7$

$1,2,4,5,6,7$

32.75

115.75

1,6

$1,2,6$

$1,2,3,6$

$1,2,3,4,6$

$1,2,3,4,6,7$

33.25

116.25

1,4

$4,6,7$

$3,4,6,7$

$2,4,5,6,7$

$1,3,4,5,6,7$

32.25

116.25

1,6

$1,6,7$

$1,2,6,7$

$1,2,4,6,7$

$1,2,3,5,6,7$

32.75

116.25

1,2

$1,2,7$

$1,2,4,6$

$1,2,3,4,7$

$1,2,3,5,6,7$

33.25

116.75

1,6

$1,4,7$

$1,4,6,7$

$1,3,4,6,7$

$1,2,4,5,6,7$

32.25

116.75

1,2

$1,2,7$

$1,2,4,6$

$1,3,4,5,6$

$1,2,3,4,5,7$

32.75

$116.75 \quad 1$

1,2

$1,2,4$

$1,3,4,7$

$1,2,4,6,7$

$1,2,3,4,5,7$

33.25 


\begin{tabular}{|c|c|c|c|c|c|c|}
\hline 115.75 & 1 & 1,2 & $1,2,6$ & $1,2,3,6$ & $1,2,3,4,6$ & $1,2,3,4,6,7$ \\
\hline \multicolumn{7}{|l|}{36.25} \\
\hline 115.75 & 1 & 1,2 & $1,2,6$ & $1,2,4,6$ & $1,2,3,4,6$ & $1,2,3,4,6,7$ \\
\hline \multicolumn{7}{|l|}{36.75} \\
\hline 115.75 & 1 & 1,2 & $1,2,6$ & $1,2,3,4$ & $1,2,3,4,5$ & $1,2,3,4,6,7$ \\
\hline \multicolumn{7}{|l|}{37.25} \\
\hline 116.25 & 1 & 1,2 & $1,2,6$ & $1,2,3,6$ & $1,3,4,6,7$ & $1,2,3,4,5,6$ \\
\hline \multicolumn{7}{|l|}{36.25} \\
\hline 116.25 & 1 & 1,2 & $1,2,6$ & $1,2,4,6$ & $1,2,3,4,6$ & $1,2,3,4,6,7$ \\
\hline \multicolumn{7}{|l|}{36.75} \\
\hline 116.25 & 1 & 1,2 & $1,2,6$ & $1,2,3,6$ & $1,2,3,6,7$ & $1,2,3,4,6,7$ \\
\hline \multicolumn{7}{|l|}{37.25} \\
\hline 116.75 & 1 & 1,2 & $1,2,6$ & $1,2,3,6$ & $1,2,3,6,7$ & $1,2,3,4,6,7$ \\
\hline \multicolumn{7}{|l|}{36.25} \\
\hline 116.75 & 1 & 1,2 & $1,2,6$ & $1,2,3,6$ & $1,2,3,4,6$ & $1,2,3,4,6,7$ \\
\hline \multicolumn{7}{|l|}{36.75} \\
\hline 116.75 & 1 & 1,2 & $1,2,6$ & $1,2,3,6$ & $1,2,3,6,7$ & $1,2,3,5,6,7$ \\
\hline 37.25 & & & & & & \\
\hline
\end{tabular}


Figures

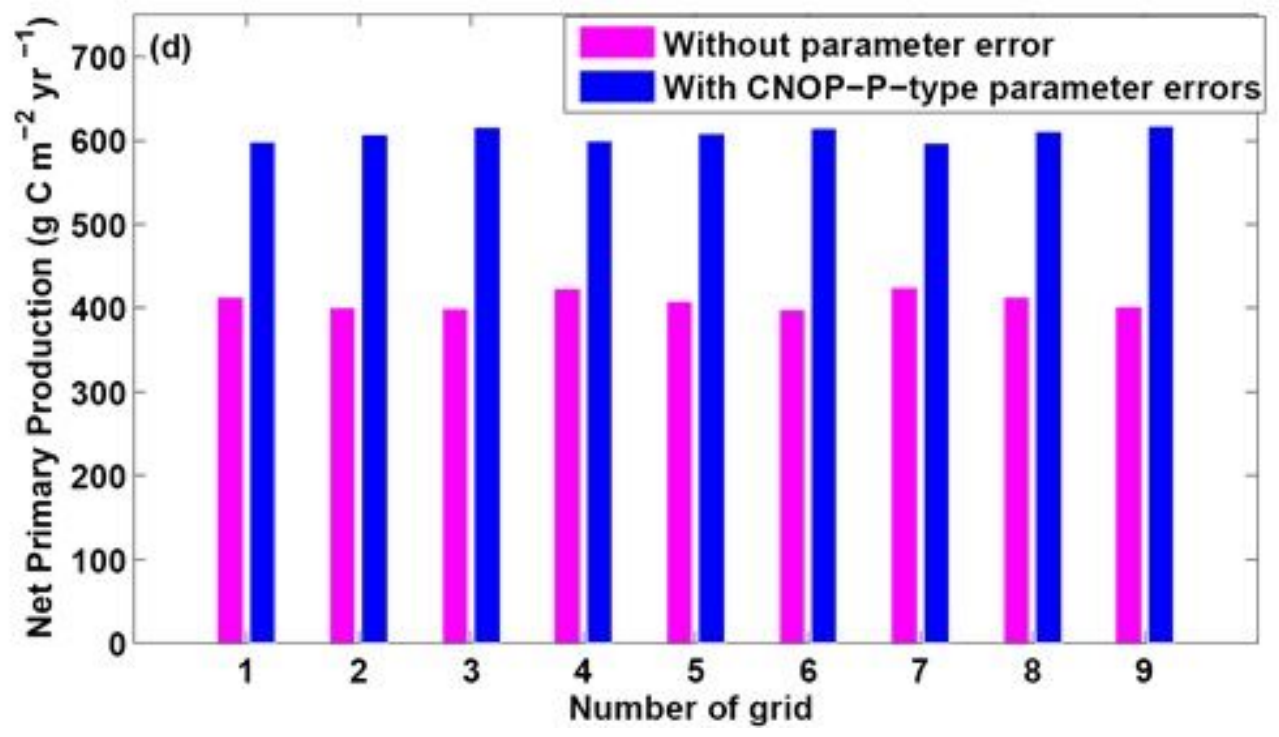

Figure 1

The modeled NPP without parameter errors and with the CNOP-P-type parameter errors for all hydrological parameters. (a): Northeastern China, (b): southern China, (c): northern China under semihumid climate conditions, and (d): northern China under arid and semiarid climate conditions.
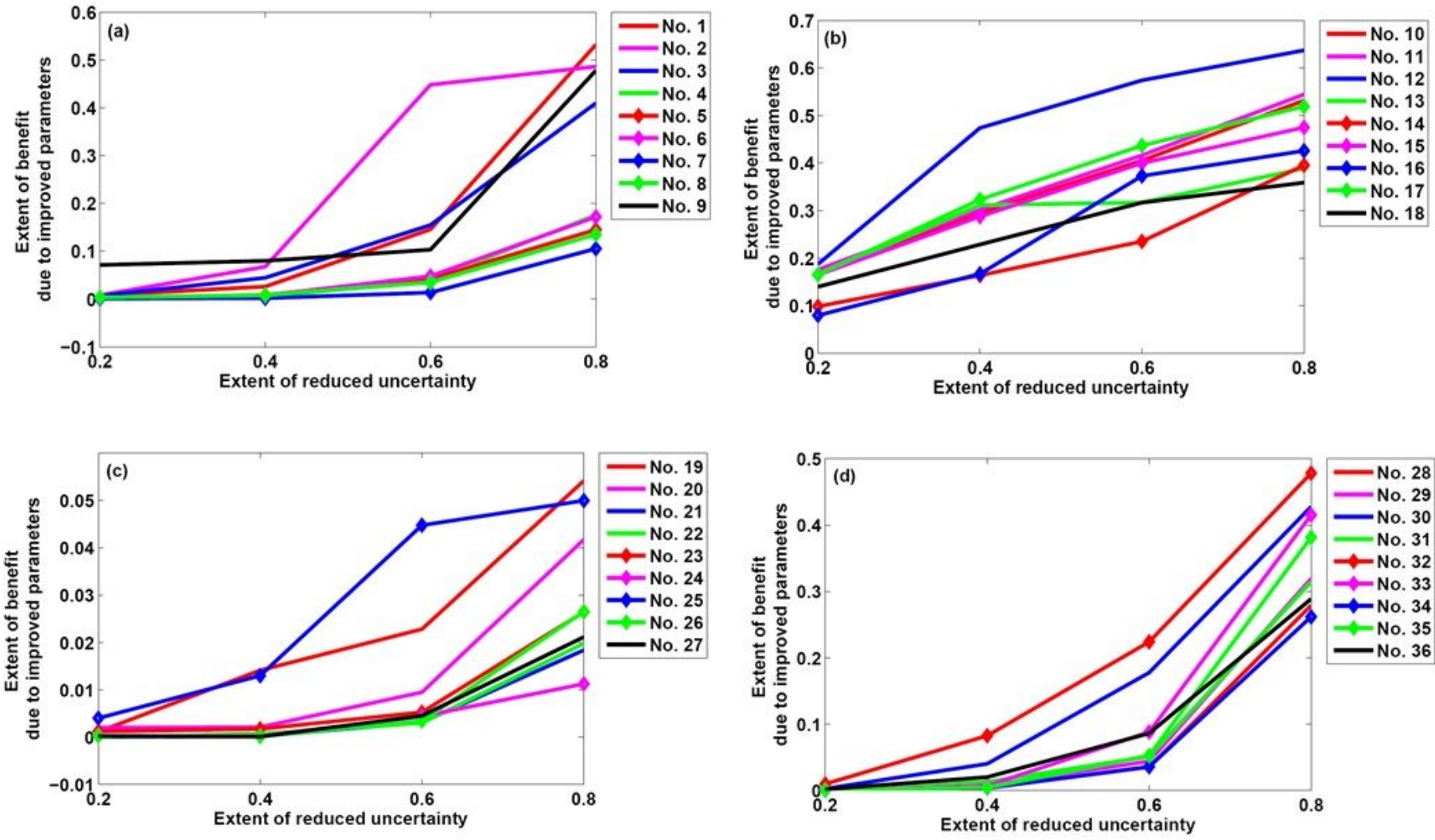


\section{Figure 2}

The benefit of modeled NPP by reducing the errors in the hydrological parameters. (a): Northeastern China, (b): southern China, (c): northern China under semi-humid climate conditions, and (d): northern China under arid and semiarid climate conditions.
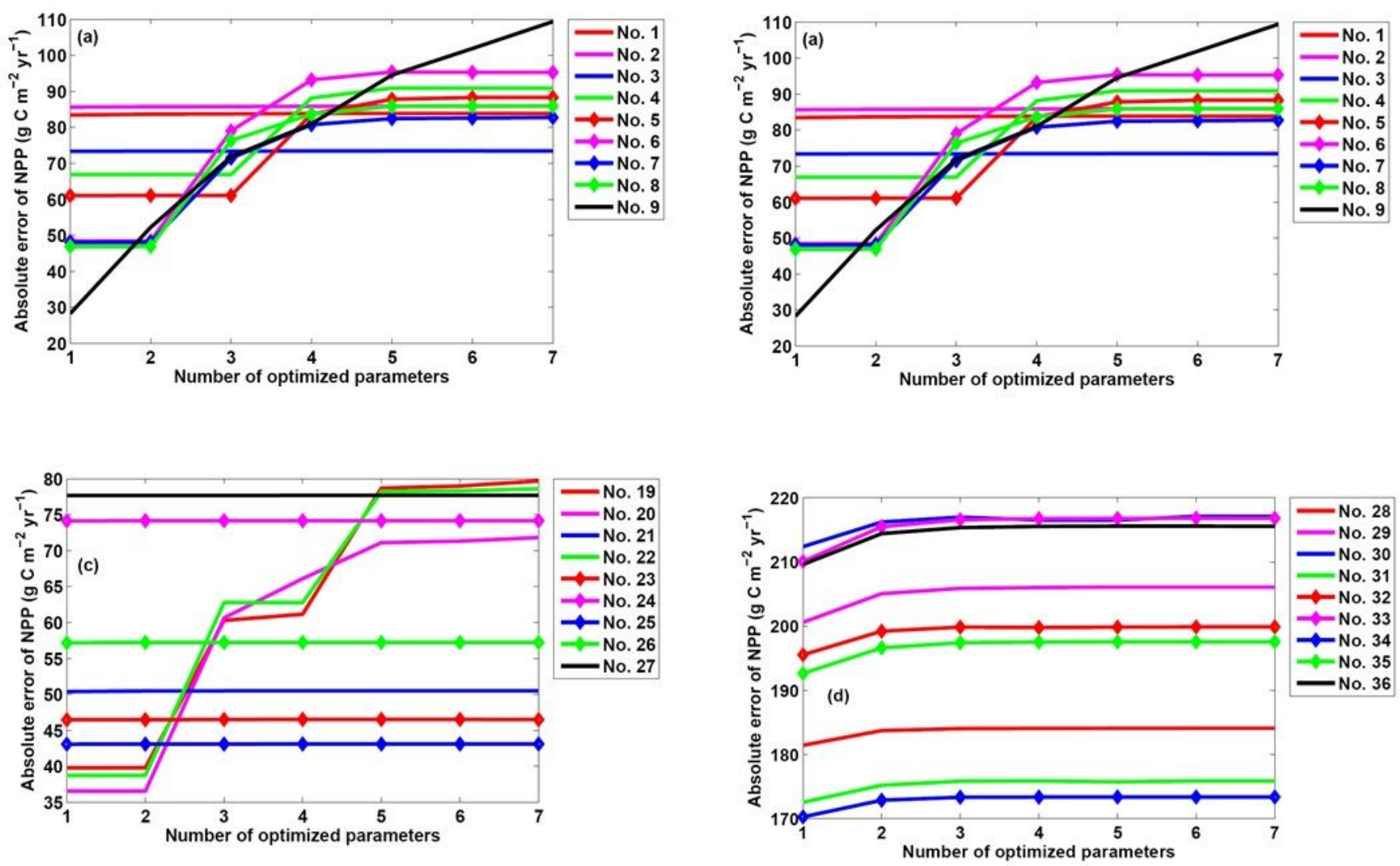

\section{Figure 3}

The errors in modeled NPP when different sizes of subsets are used for all hydrological parameters. (a): Northeastern China, (b): southern China, (c): northern China under semi-wet climate conditions, and (d): northern China under arid and semiarid climate conditions. 